\title{
A BANALIDADE DO MAL COMERCIAL NO CASO BURBERRY
}

\author{
THE BANALITY OF COMMERCIAL EVIL IN THE BURBERRY CASE
}

\author{
Joana Stelzer ${ }^{\mathrm{I}}$ () \\ Luísa Bresolin ${ }^{\mathrm{II}}$ (1) \\ Juliana de Albuquerque Pereira ${ }^{\text {III }}$ (1)
}

${ }^{\mathrm{I}}$ Universidade Federal de Santa Catarina, Florianópolis, SC, Brasil.

Doutora em Direito. E-mail: contatojoana@yahoo.com.br

${ }^{\text {II } U n i v e r s i d a d e ~ F e d e r a l ~ d e ~ S a n t a ~ C a t a r i n a, ~}$

Florianópolis, SC, Brasil.

Doutoranda em Direito Internacional e Sustentabilidade. E-mail: luisabresolin@ hotmail.com

III Universidade Federal de Santa

Catarina, Florianópolis, SC, Brasil.

Doutoranda em Direito Internacional

e Sustentabilidade. E-mail:

j.albuquerquepereira@gmail.com

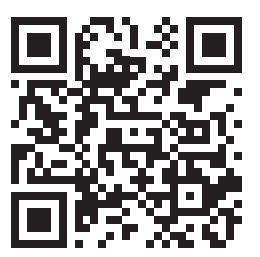

DOI: http://dx.doi.org/10.31512/rdj.v20i38.149

Recebido em: 23.04.2019

Aceito em: 07.04.2020
Resumo: $\mathrm{O}$ presente artigo se enquadra no contexto do hiperconsumo irrefletido, observável na atual sociedade de consumidores. Teve-se como objetivo descrever a Banalidade do Mal Comercial, uma ressignificação da consagrada concepção da Banalidade do Mal, de Hannah Arendt. O pano de fundo da investigaçáo teve por base a incineração de estoque da marca Burberry. Os marcos teóricos utilizados foram Hannah Arendt, Zygmunt Bauman, Gilles Lipovetsky e Joana Stelzer. Verificou-se que a divulgação da prática não afetou o lucro e o crescimento da grife nos últimos cinco anos, evidenciando-se a irreflexão e o distanciamento da ética socioambiental por parte do consumidor - características substanciais da Banalidade do Mal Comercial. Trata-se de pesquisa pura, qualitativa e de abordagem dedutiva. Quanto aos fins é descritiva, os meios foram majoritariamente bibliográficos e os resultados expostos em forma de textos.

Palavras-chave: Hannah Arendt. Banalidade do Mal. Banalidade do Mal Comercial. Burberry. Consumo.

Abstract: The present article fits in the context of reckless hyperconsumption, observable in the current society of consumers. The objective was to describe the Banality of Commercial Evil, a re-signification of the consecrated conception of Banality of Evil, by Hannah Arendt. The background of the investigation was based on the incineration of Burberry brand stock. The theoretical frameworks used were Hannah Arendt, Zygmunt Bauman, Gilles Lipovetsky and Joana Stelzer. It was verified that the divulgation of the practice did not affect the profit and the growth of the brand in the last five years, evidencing itself the irreflexion and the distancing of the social-environmental ethic on the part of the consumer - substantial characteristics of the Commercial Banality. It is a pure, qualitative and deductive approach research. Its purpose is descriptive, the resources were mostly bibliographical and the results are presented in the text form.

Keywords: Hannah Arendt. Banality of Evil. Banality of Commercial Evil. Burberry. Consumption. 


\section{Introdução}

No âmbito do estudo do consumo (ir)responsável, a Banalidade do Mal - termo cunhado por Hannah Arendt no contexto do julgamento de atos do período nazista alemão - foi ressignificado por perspectiva de Banalização do Mal Comercial, ideia que se sustenta na irreflexão dos comportamentos consumeristas e na estranha normalidade de aceitação de produtos sabidamente oriundos de práticas violadoras de direitos humanos e ambientais. Vale dizer, embora se conheçam as deletérias consequências de produtos não sustentáveis, o consumidor lida com o assunto de maneira convencional, sem lhe despertar a desconfiança de efeitos concretos e danosos no mundo real.

Sob tal enfoque, a denominada Banalidade do Mal Comercial foi retratada no caso Burberry, mediante pesquisa bibliográfica multidisciplinar e documental, com base no relatório anual da empresa e no posicionamento de entidades correlatas. $\mathrm{O}$ fato diz respeito à empresa de luxo britânica Burberry que destruiu significativa quantidade de produtos que náo conseguiu vender, objetivando proteger a marca ao tentar minimizar a quantidade de estoque excedente.

O problema de pesquisa gira sobre a seguinte indagação: de que maneira é possível referir-se à Banalização do Mal Comercial no caso Burberry, tomando como base os estudos de Hannah Arendt acerca do mal que se torna banal em virtude da irreflexão de Adolf Eichmann e que se caracteriza na sociedade contemporânea pela superfluidade das relaçóes sociais? Trabalha-se com a hipótese de que tal quadro existe na esfera comercial e que é representada pelo 'não pensar' do consumidor, ato cuja raiz encontra-se na ausência de enraizamento das relaçóes sociais. Quando a pessoa humana não conhece a si mesma como essência do existir, tampouco conseguirá ver no 'outro' parâmetros para guiar seus atos. $\mathrm{O}$ afastamento da realidade, por fim, conduzirá o consumidor para a maldade sem que perceba sua face não humana. Em virtude da ausência de reflexão será capaz de promover o mal.

Justifica-se a escolha do tema, ao avaliar os impactos da indústria da moda e a peculiaridade do setor como símbolo da sociedade contemporânea ocidental, já caracterizada por Zygmunt Bauman como sociedade de consumo. Busca-se demonstrar as similitudes entre os processos psicológicos de irreflexão de Adolf Eichmann e, em paralelo, a semelhante atitude irrefletida do consumidor pós-moderno, sob a ótica de Lipovetsky.

Por fim, avaliou-se a Banalização do Mal Comercial pontualmente, no caso Burberry, divulgado em 2018, que denota a prática de incineração de estoque de vestuário e outros artigos de luxo. Ressalta-se a importância da reflexão proposta, igualmente, à luz do Objetivo do Desenvolvimento Sustentável 12 traçado pela Organização das Nações Unidas como meta para o ano de 2030, referente a padróes de produçáo e de 
consumo sustentáveis. De acordo com essa meta, propóe-se instigar reflexóes jurídicas que busquem reorientar a tomada de decisóes no âmbito público e privado direcionadas à adoção de estilos de vida mais sustentáveis. Sob tal perspectiva, foi utilizado o marco teórico na perspectiva de Joana Stelzer que investiga a Banalização do Mal Comercial em estudos voltados acerca do Comércio Justo, especificamente na obra Direito do Comércio Internacional: do Free Trade ao Fair Trade.

Salienta-se que a escolha do caso Burberry foi oriunda da repercussão do caso, a fim de descrever a Banalizaçáo do Mal Comercial, enquanto objetivo geral. A prática não é novidade, pois é de conhecimento público que diversas outras grandes marcas atuaram em semelhante sentido para evitar, sob quaisquer circunstâncias imitações, réplicas, venda em mercado paralelo ou qualquer atitude que arrisque a desvalorizaçáo da marca. Dentre os objetivos específicos, citam-se: descrever a Banalidade do Mal em Hanna Arendt; identificar a Sociedade da Irreflexão; e, demonstrar a insensibilidade com a qual diversas organizações lidam com seus próprios produtos, alcançando a destruição de vestimentas em perfeito estado. Embora exista o esforço da marca Burberry em aspectos de sustentabilidade e também pelo exposto em sua defesa pública, no tocante aos fatos é instigante perceber um aparente paradoxo comportamental.

Quanto à natureza é pesquisa pura e relativamente à abordagem do problema classifica-se como qualitativa. Em relação ao método de abordagem, a investigação é dedutiva, pois a partir das premissas de Hannah Arendt forneceram-se razóes suficientes a favor da conclusão, especialmente quanto à possibilidade de um Mal Banal no âmbito do comércio. Em relação aos fins foi utilizado o método descritivo, já que havia um forte propósito em traçar as mudanças ocorridas na contemporaneidade e que viabilizaram um consumidor que pratica o mal sem que reconheça sua maldade na superfluidade das relaçóes. Os meios foram bibliográficos, tanto utilizando relatórios institucionais quanto obras doutrinárias nacionais e estrangeiras. Os resultados foram expostos exclusivamente em forma de textos.

\section{A banalidade do mal em Hannah Arendt e a superfluidade de Adolf Eichmann}

A filósofa judia Hannah Arendt acompanhou, na década de 60, o julgamento do ex-integrante do regime nazista Adolf Eichmann, o qual era encarregado do transporte de judeus para diversos campos de concentração. Arendt (1999) debruçou-se em análise pormenorizada do julgamento e, também, da personalidade de Eichmann, ousando, a despeito da opinião popular da época, enxergar a desconcertante normalidade e mediocridade do réu, que, imerso em um contexto de Banalização do Mal, contribuiu para perpetrar indizíveis atrocidades. 
Enquanto a coletividade e a própria mídia aguardavam que Hannah Arendt trouxesse situaçóes bombásticas e de como o holocausto mereceria ser condenado a partir do relato que ela testemunhara, a filósofa viu no discurso de Eichman a extraordinária falta de capacidade para pensar. Isso era mais importante. Tratava-se, entáo, de um misto de perplexidade e espanto que atraía a pensadora acerca da superficialidade com que Eichman descrevia seus motivos para colaborar com a morte de milhóes de pessoas.

Na obra Eichmann em Jerusalém, Hannah Arendt, à época correspondente independente do jornal estadunidense The New Yorker, realizou a cobertura completa do julgamento de Adolf Eichmann (SIQUEIRA, 2011). Naquela ocasião, a estudiosa realizou análise pormenorizada do processo e dos aspectos atinentes ao regime nazista, dedicando-se a uma profunda compreensão do comportamento, das açóes e mesmo da personalidade de Eichmann. Arendt cunhou o termo Banalidade do Mal para referir-se ao fenômeno com o qual se defrontava cada vez que se via obrigada a achar o fio condutor entre os reprováveis atos aos quais Eichmann havia dado causa e as desconcertantes normalidade e mediocridade que direcionavam o proceder e o pensar do réu.

No regime nazista, contudo, Eichmann náo fazia parte do alto comando do partido, muito embora sua participação tivesse sido, de fato, bastante decisiva. Resumidamente, em uma primeira fase do regime, quando a Solução Final ${ }^{1}$ ainda náo havia sido abertamente deflagrada, Eichmann, dentro do intrincado sistema administrativo interno partidário (nazista), era responsável pela denominada 'imigração' de judeus. Ele organizava e manejava os grupos migratórios, resolvendo questóes práticas como documentação, quantidade de pessoas por grupo e destino final. No entanto, com o endurecimento do regime - passando o extermínio total do povo judeu a ser objetivo abertamente deflagrado na organização - Eichmann ficou responsável, não mais pela 'imigraçáo', mas, por embarcar sucessivos vagóes de judeus para diversos campos de concentração espalhados pelo território do terceiro Reich.

Eichmann já não mais acreditava em 'solução para o problema judeu' que pudesse agradar os dois lados. Ele tinha pleno conhecimento de que estava embarcando centenas de milhares de pessoas para a morte por gás ou por fuzilamento. Embora em uma ou duas ocasióes, ao ser obrigado a visitar alguns campos de concentração, sua consciência tivesse vacilado, na quase totalidade do tempo ele náo se questionava sobre seus atos, apenas aceitava e seguia ordens. Eichmann chegara a afirmar por diversas vezes que "só ficava com a consciência pesada quando não fazia aquilo que lhe ordenavam” (ARENDT, 1999, p. 37).

1 Solução Final foi a expressão utilizada dentre os membros do partido nazista para fazer referência ao assassinato em massa de judeus propriamente dito. O plano, que foi concebido por Hitler muitos anos antes, começou a ser oficialmente posto em prática por volta de 1941, quando se encerrou a fase menos radical do regime (ARENDT, 1999, p. 98). 
Tratava-se então de um jovem de inteligência mediana e de sucessivos fracassos na vida escolar. Com efeito, o réu sempre teve um desempenho relativamente medíocre naquilo que costumava fazer. Embora ambicioso, tinha sido um homem de pouca iniciativa própria, preferindo obedecer ordens. Eichmann viu no 'Movimento' uma forma de construir carreira para além de sua vida rotineira e sem significado. Enquanto para Hitler tratava-se de um plano de domínio e extermínio de judeus; e; para os judeus era perseguição e horror, para Eichmann era o desempenho cotidiano de suas funçóes administrativas, representando patente superior, enfim, era mero plano de carreira. Em síntese, a ascensáo motivava e justificava suas açóes, trazendo os atos que praticava para uma estranha aceitabilidade cotidiana.

Eichmann era assustadoramente normal. Vale dizer, uma normalidade "na medida em que 'não era exceção dentro do regime nazista'". Ele era absolutamente comum dentro daquele meio, posto que, "nas condiçôes do Terceiro Reich, só se podia esperar que as 'exceçôes' agissem normalmente" (ARENDT, 1999, p 38).

O insight de Hannah Arendt, mesmo em meio a contexto de ódio e desejo de vingança em relaçáo aos nazistas, foi ter enxergado a humanidade de Eichmann, ainda que de forma majoritária se tentasse retratá-lo como o pior dosexecutores e influente membro da alta cúpula nazista. Nesse sentido, apesar "de todos os esforços da promotoria, todo mundo percebia que esse homem náo era um 'monstro', mas era difícil não desconfiar que fosse um palhaço" (ARENDT, 1999, p. 67).

A percepção de Hannah Arendt sobre a normalidade do homem que estava sendo julgado foi primordial, não para absolvê-lo de culpa ou para entendê-lo como completo incapaz, mera engrenagem em todo o processo; pelo contrário, a ideia consistia em atestar que a (falta de) humanidade de Eichmann trouxe dilemas ainda maiores e mais abrangentes.

Como era possível que aquele homem, nem excessivamente mal, nem radicalmente antissemita, conseguia conviver - e mais que isso, colaborar - com a perpetuação de todo o horror à sua volta? Contemporaneamente, poderiam aqueles que se consideram normais e capazes de distinguir com relativa precisáo o bem do mal e o certo do errado, em determinadas condiçóes e contextos, portarem-se de forma táo anômala quanto Eichmann? Estaria o homem contemporâneo em um plano moral superior? Nessa mesm linha, questiona

É ao deslocar para a contemporaneidade as questões morais suscitadas pelo caso Eichmann, que começam a se delinear, guardadas as devidas proporçóes e contextos, as similitudes e correspondências entre a irreflexão de Eichmann e a irreflexão do homem pós-moderno e, mais especificamente, do consumidor pós-moderno. 


\section{A banalidade do mal comercial: um fenômeno contemporâneo}

Dado que o ato de consumir é pressuposto e consequência da existência humana na Terra, bem como que o consumismo permeia e capilariza-se por todas as atividades humanas, não é surpreendente que no contexto de 'consumismo' possa vir a lume a maldade banal, ou ainda, o agir não refletido que habita o indivíduo normal. Sob tal vertente, a 'irreflexão' com que o consumidor contemporâneo, no contexto da sociedade de hiperconsumo, lida com as externalidades negativas que permeiam a troca comercial - em especial com aquelas relacionadas à produção ambientalmente desastrosa e humanamente imoral - constitui um fenômeno ao qual Joana Stelzer (2018) se refere como Banalidade do Mal Comercial.

Segundo a pesquisadora, não desconfia o consumidor que por detrás de baixos preços está o trabalho (semi) escravo ou a falta de sustentabilidade ambiental? Ou, ainda, que a obesidade decorre de prudutos industrializados sem nenhum componente nutricional (e, por isso, revela-se no preço raso)? Em grande parte, a crítica sociológica leva a crer que o consumismo é doença psicológica, no entanto, não estaria acima dessa alternativa a falta de reconhecimento do outro em primeiro lugar? A Bananidade do Mal Comercial emerge precisamente no vazio do pensamento ou na incapacidade de 'pensar o outro' (alteridade). O consumidor, nesse passo, é vítima e agente da sociedade desenraizada, na desincrustração evidenciada por Karl Polanyi em sua economia política, que já havia advertido: "Em vez de a economia estar incrustada nas relaçóes sociais, são as relaçóes sociais que estão incrustadas no sistema econômico. A importância vital do fator econômico para a existência da sociedade antecede qualquer outro resultado.” (POLANYI, 2012, p. 66)

Em decorrência dessa emergente realidade que assola a sociedade contemporânea, passa-se à análise dos pontos de contato procedimentais adotados tanto por Eichmann, quanto pelo consumidor pós-moderno, com destaque para a verificar a relativização do contexto que os permeia.

\subsection{A sociedade da irreflexão: consumir para viver e viver para consumir}

O consumo é atividade inerente, permanente e irremovível de tudo aquilo que é vivo. É uma condição biológica. Enquanto atividade entrópica, não há vida humana sem consumo. Consumo e consumismo não se confundem. O que hoje se pratica - e o que, mais precisamente, norteia a existência coletiva contemporânea - é o consumismo, não o consumo. Para Bauman (2007, p. 41): “Consumismo’ é um tipo de arranjo social resultante da reciclagem de vontades, desejos e anseios humanos rotineiros (...), transformando-os na principal força propulsora da sociedade (...)”. 
Sob tal ótica, o consumo, em sentido estrito, está relacionado à satisfação de necessidades. No entanto, na sociedade de consumidores, o objetivo do consumo, para além até mesmo da satisfação de desejos e vontades, é a comodificação do consumidor, ou seja, é elevá-lo à condiçáo de mercadoria vendável. $\mathrm{O}$ atual processo de consumo, dada mesmo a sua magnitude, está permeado de externalidades negativas, desde o momento da produçáo até o momento do descarte daquilo que foi consumido. A apatia com a qual o consumidor, no contexto da sociedade de consumo, lida com essas externalidades - em especial com aquelas relacionadas à produção ambientalmente desastrosa e humanamente imoral - constitui um fenômeno ao qual Stelzer se refere como Banalidade do Mal Comercial. A autora o define como sendo:

A percepção que temos da sociedade de consumo satisfeita e realizada por suas aquisiçóes, sob um sistema não equânime, sem conseguir pensar sobre seus atos de consumo ou sobre alternativas comerciais que tragam ao sistema de troca condiçóes de justiça (STELZER, 2018, p. 173).

A Banalização do Mal expressa no ato de consumir é própria do consumismo, mais especificamente da cultura consumista, a qual "é o modo peculiar pelo qual membros de uma sociedade de consumidores pensam em seus comportamentos ou pelo qual se comportam de 'forma irrefletida" (BAUMAN, 2007, p. 70, grifo nosso). O ato de consumir está, hoje, entranhado na subjetividade do sujeito. Consumir constrói e expressa, simultaneamente, essa subjetividade.

A abrangência do poder do consumismo sobre a subjetividade humana e a necessidade inarredável de permanecer perpetuamente consumindo estão relacionadas com a apatia com que o sujeito prontamente ignora o contexto de que proveio o objeto de seu consumo. É precisamente o papel central, primordial e produtor de sentido que tem o consumismo na sociedade de consumidores que faz com que o consumidor não consiga desapegar-se dessa prática, tal como ocorre contemporaneamente. Ele o consumidor - necessita do comportamento consumista para estar no mundo. Para o marketing empresarial, o comportamento do consumidor é disciplina acadêmica, é objeto de estudo, é o germe do êxito nos negócios de venda.

Portanto, no bojo do modelo de consumo esboçado, percebe-se que o consumidor médio é quase que inconsciente, quase que incapaz de pensar a sociedade de consume em que vive (STELZER, 2018). Essa irreflexáo se estende desde os processos de produçáa altamente onerosos dos pontos de vista ambiental e humano até as abissais desigualdades sociais provenientes do modelo econômico agressivo de livre mercado. Desse modo, conjugando-se a ideia de Banalidade do Mal, de Hannah Arendt, com o papel do consumo na vida do indivíduo pós-moderno, é possível demarcar situaçóes e modos de proceder desse último, no qual se manifesta a irreflexão e a apatia que vincava o perfil de Adolf Eichmann. 
A semelhança de ambos está na solidão da alma e na não pertença ao outro humano, fato revelador das mais desesperadas situaçóes existenciais que o ser humano pode ter. A superfluidade dessas relaçóes inter-humanas já desde a Revolução Industrial expressava a emergente sociedade de massa: atomizada e vazia de sentido, conforme se passa a descrever.

\subsection{A banalidade do mal na sociedade consumerista}

Em "Eichmann em Jerusalém", Hannah Arendt destaca uma característica de Eichmann que se considera aplicável à expressiva massa de consumidores no ato de consumir:

[...] uma falha mais específica, e também mais decisiva, no caráter de Eichmann era sua quase total incapacidade de olhar qualquer coisa do ponto de vista do outro [...]. Quanto mais se ouvia Eichmann, mais óbvio ficava que sua incapacidade de falar estava intimamente relacionada com sua incapacidade de pensar, ou seja, de pensar do ponto de vista de outra pessoa. Não era possível nenhuma comunicação com ele, não porque mentia, mas porque se cercava do mais confiável de todos os guarda-costas contra as palavras dos outros, e, portanto, contra a realidade enquanto tal. (ARENDT, 1999, p. 62).

Logo, Eichmann 'protegia-se' da ultrajante realidade ao seu redor - da qual fazia parte e com a qual colaborava - por meio do distanciamento irreflexivo e apático. Faltavalhe a capacidade de empatia, de enxergar-se no outro, assim como falta ao consumidor, que não se enxerga, por exemplo, no trabalhador explorado que produziu o objeto que está prestes a adquirir.

O distanciamento é verdadeiro véu de proteção contra a realidade, cuja existência é sabida, mas que, consciente ou inconscientemente, o consumidor pós-moderno guarda em apartado, em dimensão alternativa da existência, para que possa dar prosseguimento ao ato de consumo sem maiores inconvenientes. Ou seja, sem ater-se a todas as implicaçóes econômicas, sociais, ambientais, e até mesmo políticas, daquele ato. Isso porque o consumidor "na qualidade de um ser despolitizado, não tem moral, não tem capacidade para julgar ou para discernir, é tudo assustadoramente normal” (STELZER, 2018, p. 179). Simplifica-se e justifica-se o comportamento irrefletido.

Conforme já assinalado, Eichmann não era, a despeito das atrocidades com as quais corroborou, um tipo excepcional de monstro inescrupuloso. Sua natureza mais ou menos comum é registrada por Hannah Arendt, quando transcreve os relatos do réu sobre as vezes em que se viu obrigado a visitar determinados campos de concentraçáo ${ }^{2}$.

2 Ao olhar, de longe, um grupo de judeus nus entrado em um caminhão dentro do qual foram mortos por gás e cujos corpos - ainda moles - foram logo em seguida atirados uma imensa vala que já os aguardava, Eichmann afirmou ter ficado bastante perturbado. Disse que não conseguia olhar e que tinha que "desaparecer". Eichmann não era necessariamente sádico, muito pelo contrário, das poucas vezes em que foi brutalmente confrontado com a realidade, sentiu-se profundamente atingido. 
Nesse sentido, muito embora trabalhasse coordenando o transporte - e não diretamente o extermínio - de judeus, Adolf Eichmann sabia exatamente o que estava fazendo, chegando a sentir, em determinadas ocasióes, choque e horror. E, a despeito de tais sentimentos, Eichmann sabia para qual local e qual fim estava mandando aquelas pessoas. E mais, em que pesem suas afirmações em tribunal, ele possuía uma escolha, "[...] sabemos como era fácil para os membros dos esquadróes de extermínio abandonar seus postos sem grandes consequências" (ARENDT, 1999, p. 107). Não havia, para ele, nenhum perigo de vida, a não ser o 'mal-estar' da desobediência.

De forma similar se comportam os consumidores. Como Eichmann, o consumidor pós-moderno tem, sim - ainda que em níveis variados - a possibilidade de escolha. Existe, ainda que vaga, a ideia das dimensóes catastróficas da máquina de produção industrial operada por multidóes de miseráveis, trabalhadores escravizados e furtados de sua dignidade. Acontece que, para o consumidor pós-moderno, assim como para Eichmann, escolher um proceder diferente implica uma tomada de atitude, implica 'agir ativamente' e não mais passivamente, apenas dando seguimento ao que é esperado dele. Eichmann recebia ordens de seus superiores, de modo que uma vida sem diretrizes, sem código de conduta ao qual pudesse recorrer quando necessário lhe deixava vacilante, inseguro, para não dizer verdadeiramente perdido.

Nesse contexto, dirigir-se ao grande centro comercial e adquirir, por um preço módico, os lançamentos da semana na gigantesca rede de fast fashion, precisamente por ser o comportamento esperado do consumidor pós-moderno - para o qual o terreno já se encontra preparado e o ambiente é propício - além de ser prazeroso, é fácil. Desviar dessa narrativa requer, não apenas abrir mão da parcela do prazer que o consumismo cíclico enseja, mas também implica iniciativa do sujeito, dito de outro modo, exige ação de quem pensa e de quem se responsabiliza por suas atitudes. Nesse momento, emergirá o contraste com o proceder da maior parte das pessoas do seu grupo, sob risco de ser rotulado de excentricidade e de quem anda na contramão da história.

Nas diversas esferas do consumo - dos alimentos de primeira necessidade à vestimenta, dos produtos de limpeza às embalagens de plástico, dos cosméticos aos meios de transporte - optar por produtos alternativos requer, antes, disposição para a reflexão. É precisamente nesse momento que falha o consumidor contemporâneo. $\mathrm{Na}$ contínua tarefa de consumir ${ }^{3}$, o sujeito "retrata sua relativizaçáo enquanto humano, pois o comércio - acredita - não é seara para discussões de direitos ou de justiça. Relativizado e supérfluo, esse sujeito é agente e vítima dessa banalização" (STELZER, 2018, p. 173).

3 O caráter contínuo e infindável do consumo dá-se graças à lógica do desperdício. Sobre isso, Baudrillard (2014, p, 40) aduz que "o desperdício, longe de figurar como resíduo irracional, recebe uma função positiva, substituindo a utilidade racional numa funcionalidade social superior e se revela, no limite, como função essencial - tornando-se o aumento da despesa, o supérfluo, a inutilidade ritual do 'gasto para nada', o lugar de produção de valores, as diferenças e do sentido - tanto no plano individual como no plano social.” 
Nesse sentido, Eichmann e muitos homens como ele aliviavam suas consciências com a ideia de que estavam fazendo parte de algo muito maior e mais importante, e que, portanto, naturalmente difícil de aguentar (ARENDT, 1999, p. 121). Da mesma forma, muito da passividade e aquiescência do consumidor contemporâneo pode advir da sua percepção do mundo como um ambiente naturalmente injusto, a respeito do que muito pouco poderia alterar. Stelzer (2018) entende que o consumismo atual teria substituído o totalitarismo em determinadas nuances, no sentido de que ambos desumanizam, despersonalizam e anulam a individualidade do sujeito, de modo que sua capacidade de contextualização e julgamento se vê comprometida. Sobre esse consumismo totalizante, aduz Stelzer (2018, p.175): "A injustiça acaba sendo um comportamento normal e aceitável, enquanto o mal é banalizado. Se o seu próprio valor - enquanto pessoa digna - foi relativizado, então se torna muito difícil exigir desse ser blasé um comportamento justo em suas compras cotidianas.”

O afastamento da realidade é característica comum ao consumidor médio e aos homens como Eichmann. Para esse último, a distância era tal que, quando o interrogador da polícia perguntou a ele “[...] se a diretiva de evitar 'sofrimento desnecessário' não era um pouco irônica, uma vez que o destino daquelas pessoas era a morte certa, ele nem mesmo entendeu a pergunta” (ARENDT, 1999, p. 127). Para Eichmann, o assassinato, de tão comum, já não era apreendido pela sua mente como algo pior que o sofrimento em si.

Daí também é possível traçar um paralelo com a lógica pela qual opera o intelecto do consumidor pós-moderno. Exposto diariamente a um expressivo número de tragédias e calamidades de toda ordem advindas de distintas partes do globo, seja pelos noticiários ou pela social media, é possível observar algo como uma anestesia ou, mesmo, uma estratégia de sobrevivência dos sentidos e da capacidade de comoção do indivíduo médio. Quando tudo é importante demais, nada mais é tâo importante.

$\mathrm{O}$ processo de dissociação para com a realidade que experimenta o consumidor facilita - e também é fruto delas - a irreflexão e a incapacidade de empatia, num movimento cíclico de retroalimentação. E, para garantir a continuidade do referido processo, é de essencial importância, assim como foi para Eichmann, que o indivíduo entorpecido olhe ao seu redor e se sinta respaldado pelo restante da sociedade. Conforme Observou Arendt (1999, p. 143) "Eichmann contou que o fator mais potente para acalmar a sua própria consciência foi o simples fato de não ver ninguém, absolutamente ninguém, efetivamente contrário à Solução Final”.

Nesse sentido, a legitimação social desempenha papel essencial no processo de banalização do mal. Para Eichmann, essa legitimação tinha como consequência o fato de que "Ele não precisava 'cerrar os ouvidos para a voz da consciência', como dizia o preceito, não porque ele não tivesse nenhuma consciência, mas porque sua consciência 
falava com 'voz respeitável', com a voz da sociedade respeitável a sua volta”. (ARENDT, 1999, p. 143).

Sobre isso, Arendt conclui que "[...] onde todos, ou quase todos, são culpados, ninguém é culpado" (ARENDT, 1999, p. 301). Essa máxima de aplica à sociedade de consumidores. Nela, o consumo de produtos cultivados com insumos químicos altamente danosos ao meio ambiente e aos seres humanos, a compra de roupas e acessórios provenientes de trabalho escravo ou ambientalmente nocivo, o consumo supérfluo e o desperdício excessivo em geral são ações ainda consideradas normais e rotineiras, que passam despercebidas pelo crivo moral da sociedade pós-moderna. Sob respaldo do inconsciente coletivo e, muitas vezes, legitimado pelos recursos midiáticos, o indivíduo desobriga-se de sentir culpa.

Do mesmo modo, passados alguns meses do 'choque inicial' de Eichmann com as práticas pertinentes à Solução Final, o autor dos fatos adaptou-se às circunstâncias como elas eram. Ressalta-se, Eichmann não era um monstro, muito embora pudesse ser bastante reconfortante acreditar que ele o fosse. Afinal, isso eximiria o cidadáo do cotidiano de com ele identificar-se, afastando de pessoas comuns agir tal e qual. Acontece que se trata exatamente da situação contrária. Segundo Hannah Arendt (1999, p. 299):

O problema com Eichmann era exatamente que muitos eram como ele, e muitos não eram nem pervertidos, nem sádicos, mas eram e ainda são terrível e assustadoramente normais. [...] essa normalidade era muito mais apavorante do que todas as atrocidades juntas, pois implicava que [...] esse era um tipo novo de criminoso, efetivamente hostis generis humani, que comete seus crimes em circunstâncias que tornam praticamente impossível para ele saber ou sentir que está agindo de modo errado.

O panorama geral levava a crer que, se Eichmann - pessoa comum que era sob determinadas condiçóes - chegou a tais extremos, o consumidor pós-moderno relativamente comum, imerso em uma sociedade de hiperconsumo totalizante- está fadado à irreflexão e à indiferença. No entanto, há aqueles que, na contramão de tais constataçóes, consideram o comportamento do consumidor pós-moderno normal. Ainda, ousam antever o futuro com certo grau de otimismo.

A sociedade atual é "voltada para os prazeres e interesses imediatos", sendo, pois, "indiferente às consequências de longo prazo", tudo isso em meio a "um processo louco que origina a poluição do ambiente, a erosão da biodiversidade e o aquecimento global”. Sob outra ótica, o autor acredita no surgimento dos auterconsumidores, que já perfariam 15 a 20\% dos consumidores e os quais, conscientemente - e, muitas vezes, aceitando pagar mais caro por isso - "optam por produtos éticos, recusam a identificação com marcas, compram alimentos biológicos e questionam-se relativamente ao impacto ambiental dos produtos". (LIPOVETSKY, 2006, p. 291; 294).

O auterconsumidor consite na versão evoluída, a fase seguinte do hiperconsumidor. Embora encontre esteio nas próprias tendências de mercado atuais, a construção teorética 
de Lipovetsky incorre em demasiado otimismo, pois, em grande parte do mundo - na quase totalidade da América Latina, por exemplo - a lógica do hiperconsumismo irrefletido impera vitoriosa ainda rumo ao seu apogeu. Afinal, diversas são as faces do colonialismo. Não bastasse, toda sorte de retrocessos normativos ambientais, trabalhistas, políticos e sociais, aliados às pressóes de setores detentores de vertiginosa parcela de poder - como agrobusiness - tendem a comprometer sobremaneira a reprodução do auterconsumidor, bem como sua migração para a base da cadeia de consumo populacional.

$\mathrm{O}$ auterconsumo restringe-se à minoria esclarecida e privilegiada, para a qual o consumo reflexivo, consciente e transformador, longe de perfazer um estorvo, contribui para construçáo de sua subjetividade e de seu autoconceito, completando o ciclo inesgotável de comodificação e ressignificação apontado por Bauman.

Nesse sentido, a indústria da moda, dado seu viés apelativo e sedutor, consiste em significativo empecilho para a reprodução do auterconsumidor. Nela, a Banalidade do Mal consumerista faz-se notar de forma nítida. Isso porque, muito embora grande parte das externalidades negativas que permeiam todo o ciclo de vida dos produtos dessa indústria sejam relativamente evidentes, não se nota reação equivalente por parte dos consumidores. Sob essa toada, passa-se a avaliar o caso de queima de estoque da marca Burberry, loja de luxo de vestuário e acessórios, ocorrido em 2018.

\section{Incineração de estoque: caso Burberry}

As críticas às externalidades negativas na indústria da moda vêm crescendo. Uma série de impactos é passível de ser notada ao longo do ciclo de vida dos produtos para alimentar a chamada indústria da moda, fato que permeia o processo de produçáo, consumo e descarte de bens. A difusão de informação sobre as consequências sociais e ambientais altamente nocivas são retratadas e exemplificadas no documentário The True Cost (O verdadeiro custo da moda) (THE TRUE COST, 2015). As técnicas de obsolescência empregadas na produção de vestuário, tal qual a utilização de produtos de baixa qualidade e, consequentemente, durabilidade, têm sido percebidas, especialmente com especial relevo no ramo do fast fashion (consumo rápido).

Os desrespeitos aos direitos humanos são flagrados e ressaltados pelo movimento Fashion Revolution, acompanhado de denúncias de trabalho equiparado a escravo (na acepção moderna) pelo Ministério Público, Organização Internacional do Trabalho (OIT) e mídias independentes.

Se, por um lado, a obscuridade da moda tem sido desvelada e gera sensibilização do público, por outro lado é difícil identificar a mudança no padrão de consumo decorrente de atos nefastos à vida e ao meio ambiente, fato que se relaciona ao comportamento descrito anteriormente. No fito de demonstrar a Banalidade do Mal comercial na 
contemporaneidade, especialmente tangente ao desrespeito ecológico, passa-se a avaliar específica prática relativa ao processo de destinação final de mercadorias.

Primeiramente, apresenta-sebreveretrospectivahistóricaacercadodesenvolvimento da marca, antes de partir para a descrição dos fatos relativos ao evento da incineração de estoque excedente da marca Burberry em 2017, amplamente divulgado em 2018. No segundo tópico, avalia-se o caso propriamente dito sob o conceito de Banalizaçáo do Mal Comercial segundo o princípio da sustentabilidade.

\subsection{Burberry: marca e fatos}

Burberry é a marca criada em 1856 por Thomas Burberry, com a principal missão de desenvolver um vestuário confortável para proteger as pessoas do frio britânico. Em 1879 a empresa foi responsável pelo invento da gabardina, tecido incialmente fabricado a partir da lanolina, um subproduto da lá, e também nas versóes de lá pura ou misturada com algodão. O tecido foi patenteado em 1888. (BURBERRY, 2019b).

O casaco que tornou a marca icônica foi desenvolvido entre 1914 e 1918, durante a Primeira Guerra e visava à praticidade em combate, com revestimento duplo, espécie de capa nos ombros para escorrer a chuva e até anéis para engatar granadas. Trata-se do trench coat, que pode ser traduzido como gabardine, mas, a tradução literal seria casaco de trincheira. $\mathrm{Na}$ década de vinte, a estampa xadrez na cor bege com listras pretas e vermelhas torna-se marca registrada da Burberry. Na última década, percebe-se o engajamento da marca no sentido de implementação de práticas de impacto socioambiental positivo.

Em 2010, a Burberry foi a primeira grife de luxo a integrar o comércio justo (Ethical Trading Initiative - ETI). Em 2016, passou a ser reconhecida como líder no índice de sustentabilidade da bolsa americana Dow Jones na categoria de artigos de luxo, têxtil e vestuário. No ano de 2014 (GREENPEACE, 2019) a Burberry se comprometeu em eliminar de sua produção substâncias tóxicas.

$\mathrm{Na}$ continuidade, no ano de 2018, com o intuito de demonstrar solidariedade à causa LGBT, a marca criou a versão colorida da sua estampa exclusiva para a coleção de fevereiro. No mesmo ano, a grife de luxo passou a fazer parte da fundação Ellen MacArthur, que visa às soluçóes ecológicas para a indústria da moda, desde a fabricação até o descarte das roupas. (ELLEN MACARTHUR FOUNDATION, 2019). Essa iniciativa, denominada Make Fashion Circular ou Faça a Moda Circular, em referência à economia circular, é patrocinada por empresas de grande porte como a Fundação C\&A e a Fundação Wallmart. (L'OFFICIEL, 2019).

Nota-se, a partir de um breve histórico, que se trata de uma marca com iniciativas de sustentabilidade socioambiental, especialmente por compor o ETI e a Fundaçáo Ellen MacArthur. No entanto, em junho de 2018, a renomada marca de artigos de luxo publicou seu relatório anual, no qual revelava de forma bastante discreta, dentre as 200 
páginas, que promoveu a 'destruição física de bens', correspondente ao valor de $£ 28.6$ milhóes ou cerca de $\mathrm{R} \$ 140$ milhóes. Uma série de matérias jornalísticas divulgou o fato que, de forma mais clara, teria sido a queima literal de estoque. Algumas mídias ressaltaram que seria uma prática comum no mercado da moda (INFOMONEY, 2019) e outras rechaçaram o descaso ético e ecológico (THE GUARDIAN, 2019).

Nessa ocasiáo, a ThredUp - reconhecida loja virtual de revenda -fez uma carta aberta à Burberry. No documento, um convite para que no futuro lhes fossem enviados os bens ao invés da destinação de incineração, a fim de reinseri-los na economia, mediante a doação de $100 \%$ do lucro a entidades ambientalistas. $\mathrm{Na}$ ocasião, frisou sobre a crise ambiental enfrentada por vastas camadas da população, agravada pela indústria fashion; e, informou a respeito da projeção de um quarto das emissóes de carbono em 2050 pelo setor. (WEINBERG, 2019)

Em defesa à imprensa, a Burberry alegou a sustentabilidade da prática (environmental friendly), tendo em vista a técnica de captura de carbono empregada. Informou, também, que a marca é cuidadosa quanto à minimizaçáo de excesso de estoque e que mantém a busca pela redução e revalorização dos resíduos (BBC, 2019). A prática não foi inédita. $\mathrm{O}$ relatório anterior, referente ao ano de 2016 indicava que o custo das mercadorias destruídas havia sido de $£ 18.8$ milhóes. Em 2015, praticamente o mesmo valor se revelara em semelhante prática, ou seja, destruiçáo de $£ 19.7$ milhóes (BURBERRY, 2019c). No relatório de 2018 não havia ficado claro se a quantidade do estoque excedente aumentara em 2017 ou somente a sua valorização.

Em resposta, em setembro de 2018, a Burberry declarou em seu site oficial o comprometimento com princípios da sustentabilidade, reafirmando sua agenda para 2022 nos termos propostos pela Fundação Ellen MacArthur, especialmente pela existência de um grupo para pesquisa de materiais sustentáveis e a eliminação da utilização de pele verdadeira em suas coleções. Ademais, a empresa destacou específicas práticas sustentáveis: utilização de $21 \%$ do algodáo utilizado ser Better Cotton Initiative (BCI) com meta de $100 \%$ para 2022; neutralização da emissão de carbono em suas operaçóes; redução de agua e energia; comprometimento com programas sociais em Londres e Yorkshire; parceria com Oxfam no Afeganistão para a produção sustentável da indústria de cashmere; aproveitamento de 130 toneladas de resíduos de corte da produção com couro pela Elvis e Kresse nos próximos 5 anos; entre outros. Em que pesem os compromissos assumidos, mercadorias estimadas em quase R\$ 450 milhões foram incineradas pela Burberry entre 2013 e 2018. Avaliar a correlação da prática de incineração à Banalização do Mal Comercial é o que a investigação passa a fazer. 


\subsection{A incineração dos bens e a banalização do mal comercial}

O deslumbramento da sociedade de consumo tem por consequência a privação de sensatez em relação às práticas insustentáveis da indústria da moda, ora exemplificada pela incineração do estoque da Burberry. A aparente normalidade de incineração de roupas contrasta com deficiências sociais que se espraiam por vastas comunidades miseráveis, sob o manto da eficiência de mercado relativa à manutençáo de preço decorrente de oferta e demanda. A prática foi descrita pela mídia como 'prática comum do mercado', no fito da manutenção da valorização das mercadorias. A questão, em verdade, gira sobre o fato de ser inconcebível para a imagem da marca que seus produtos fossem vendidos em promoçóes para um público não direcionado. $\mathrm{O}$ custo do estoque igualmente se revela outra justificativa, considerando, sob a ótica da perversidade comercial, que a possibilidade de doação restava descartada.

Entre o risco da perda de vendas por subprodução e o risco do excesso pela superprodução, a marca optou pela segunda alternativa, independentemente de externalidades negativas socioambientais que poderiam decorrer. Os resultados econômicos da Burberry ao longo dos cinco anos em que se constatou a prática de eliminação do excedente foram positivos. Extrai-se da cotação do mercado de ações que no período entre 2013 e 2018 houve valorização dos ativos da Burberry, apesar da oscilação negativa entre 2015 e 2016 (ADVFN BRASIL, 2019). Lê-se no relatório anual de 2018 que desde 2014 houve o crescimento da receita, com leve baixa de 1\% na relação 2016/2017. A receita de $£ 2,330$ milhóes em 2014 aumentou para $£ 2,733$ milhóes em 2018, ou seja, superior a R\$ 13 bilhóes. (BURBERRY-B, 2019d, p.28). Com isso, verifica-se que a que a marca não teve seu lucro diminuído e tampouco a desvalorização das açóes, enquanto realizava a prática de queima de estoque.

Aufere-se dos dados que a realização de incineração não impactou as vendas de forma negativa, fato que pode ser atribuído tanto à falta de informação ou à típica Banalidade do Mal Comercial. A segunda hipótese configura maior plausibilidade, considerando a publicidade dos relatórios anuais constantes no site da marca, amenizada pelo eufemismo da incineração, sutilmente citada como "bens destruídos fisicamente", no original, finished goods physically destroyed (BURBERRY, 2019a, p.167). O conceito de Banalidade do Mal Comercial aduz à iniquidade:

A Banalidade do Mal comercial diz respeito à percepção que temos da sociedade de consumo satisfeita e realizada com suas aquisiçóes, sob um sistema não equânime, sem conseguir pensar sobre seus atos de consumo ou sobre alternativas comerciais que tragam ao sistema de troca condiçóes de justiça. (STELZER, 2018, p.173)

A injustiça latente é social e ecológica. Por um lado, a pobreza que contrasta o desperdício de bens materiais e a desigualdade distributiva; e, por outro, a externalidade negativa sobre o ambiente, potencializando os efeitos da mudança climática, diminuindo 
o tempo de vida útil de aterros sanitários e promovendo a extração de nova matériaprima decorrente da inutilizaçáo dos resíduos. Dados da Organização das Naçóes Unidas (ONU) de 2019 apontam que cerca de 1,3 bilhão de pessoas de 101 naçóes são consideradas "multidimensionalmente pobres", ou seja, a pobreza que não se reduz ao baixo rendimento, mas envolve indicadores ligados à saúde e à educação que as mantêm reféns dessas condições. (UN, 2019)

Francois Souchet, responsável pelo movimento referido de Moda Circular (Make Fashion Circular), atenta para o fato de 53 milhóes de toneladas de fibras têxteis serem utilizadas para fabricacão de roupas por ano, das quais $73 \%$ têm por destino os aterros ou a incineração, enquanto $12 \%$ é desperdiçado na produção e 0,5 milhão de tonelada de microfibras vazam para os oceanos. Do total, somente $1 \%$ é reciclada e se torna roupa nova. Alerta, ainda, que a indústria da moda emite gases de efeito estufa na proporção de todos os voos e transportes internacionais combinados (o que equivale a 1,2 bilhão de toneladas por ano), ritmo que prenuncia a responsabilidade de $25 \%$ das emissóes de carbono para o cenário de 2050. (THE NATIONAL, 2019).

A fim de promover a sustentabilidade, a indústria da moda necessita considerar todo o ciclo de produção, desde a fabricação até o descarte e a gestão de resíduos, em processo de logística reversa pós-consumo- fator crucial para mudança paradigmática. Visa-se a um processo de produçáo econômico, o aproveitamento máximo do tecido no enfesto (procedimento de corte), distribuição local das mercadorias, durabilidade das peças e possibilidade de reutilização do resíduo. No caso em tela cumpre frisar que há uma problemática em relação à própria caracterização do resíduo, que sequer se enquadra na categoria de pós-consumo, de modo que, em tais casos, revela-se imprescindível o aproveitamento do produto intacto.

O princípio da hierarquia do direito dos resíduos determina que o processo de menor dispêndio energético seja aplicado: o aproveitamento dos bens é menos custoso do que a reutilização, que por sua vez é menos custoso que a reciclagem. E, preponderante sobre as opçóes elencadas, prima-se pela não geração do resíduo, o que requer o planejamento da produção no intuito de evitar superprodução.

Ao longo da trajetória levantada no tópico anterior, a marca demonstrou empenho na aplicação de práticas de sustentabilidade, circunstância que não a isenta da crítica quanto à antiética destinação final de bens em estado perfeito no contexto contemporâneo e planetário de desigualdade social e crise ambiental. Outras contradiçóes vieram à tona da leitura da declaração da Burberry à imprensa, como a questão do direito dos animais, pois embora tivesse eliminado o uso de pele animal, manteve o uso de couro e cashmere (produçóes que levam a resíduos derivados de metais sólidos e confinamento animal, respectivamente) 
Em outubro de 2018 o Grupo Burberry assinou o Compromisso Global para a nova economia de plásticos, campanha liderada pela fundação Ellen MacArthur, que contou com 250 signatários (THE NEW PLASTICS ECONOMY FGLOBAL COMMITMENT, 2019). A declaração do comprometimento da Burberry em não mais realizar a incineraçáo de bens em estoque trouxe esperança quanto à possibilidade de grandes marcas passarem a adotar soluções sustentáveis em toda linha de produção.

\section{Conclusáo}

'Eichmann em Jerusalém' revelou a superfluidade não somente de um humano, mas, de uma sociedade insensível ao outro. A conduta de Adolf Eichmann, funcionário que serviu o estado nazista alemáo foi a matriz necessária para que a perspicácia de Hannah Arendt revelasse a irreflexão e a incapacidade de empatia como determinantes para o cumprimento de ordens desumanas. O problema era maior do que ter feito o mal, pois o mais grave era que o mal tinha se tornado banal.

A Banalidade do Mal em Eichmann, do ponto de vista fenômenológico é passível de ser estendido ao comportamento do consumidor pós-moderno ocidental. Bauman e Lipovetsky corroboram com essa tese, ou seja, que a irreflexão rege a regra do consumo, independentemente das consequências de longo prazo. Trata-se de um desafio ao pensamento humano, pois o consumo é capaz de trazer essa inabilidade de 'pensar' verdadeiramente, de perceber as pessoas nas suas desgraças por detrás das mercadorias adquiridas. $\mathrm{Ou}$, sob outro aspecto, de perceber as tragédias ambientais que se escondem em processos produtivos destruidores da natureza. Tudo isso acontece sem que haja perversidade ou sadismo como intenção consumerista, pelo contrário, tudo acontece de maneira terrivelmente normal.

A vida em massa revela o humano não gregário, desenraizado do social, ser estreitado no grande coletivo. Um consumidor que há muito olvida ser partícipe de uma grande rede interdependente, pelo contrário, passou a ser prisioneiro das coisas, é animal laborans arendtiano ainda convivente cosmopolita do outro humano nas grandes cidades, mas que desconhece o outro enquanto essência.

Verificou-se que no caso Burberry, a partir da divulgaçáo do seu relatório 2018, no qual se incluiu a incineração de mercadorias, embora a prática devesse ter chamado a atenção dos consumidores e causado espanto, não surtiu maiores feitos para a instituição. Passivos, os consumidores não se estremeceram com a queima de roupas de qualidade, avaliaram como 'normal'. $\mathrm{O}$ argumento de a mercadoria acolher alguém que passa frio não resistiu diante da possibilidade de arranhar a imagem da marca. Vale dizer, a prática não gerou efeitos de queda de consumo, tampouco houve a desvalorizaçáo dos ativos do grupo Burberry, fato constatado por intermédio da verificação dos dados de 2013 a 
2018 da consulta aos relatórios anteriores e, também, dos índices da bolsa de valores. Em síntese, confirmou-se que a referida prática - não inédita entre grandes organizações - não acarretou perda de lucro significativa à empresa. Nem mesmo a sutil linguagem utilizada no relatório para retratar a incineração enquanto "destruição física de bens" suavizou ou mascarou a prática, circunstância que não impediu sua interpretação e divulgação.

O fato, em verdade, revelou prática contrária ao comprometimento da marca com a sustentabilidade, já que havia sido a primeira grife de luxo a integrar o Comércio Justo por intermédio da ETI, a ter compromisso com a assinatura do Make Fashion Circular e a firmar o Compromisso Global para a nova economia de plásticos, campanha liderada pela fundação Ellen MacArthur. A resposta pública da marca no site oficial informou a proibição da prática para o futuro.

O caso retratou o distanciamento do consumidor com a ética socioambiental, caracterizando a irreflexão típica da Banalidade do Mal Comercial. A divulgação da prática não afetou o lucro e crescimento da marca nos últimos cinco anos. O princípio da sustentabilidade, teoricamente compromisso da Burberry foi gravemente afetado, tendo sido reafirmado após o episódio.

\section{Referências}

ADVFN BRASIL. Advanced Financial Network. Cotação Burberry Grp. Disponível em: https://br.advfn.com/bolsa-de-valores/lse/BRBY/cotacao. Acesso em: 25 fev. 2019.

ARENDT, Hannah. Eichmann em Jerusalém: um relato sobre a banalidade do mal. Tradução de José Rubens Siqueira. São Paulo: Companhia das Letras, 1999.

BAUDRILLARD, Jean. A sociedade de consumo. Tradução de Artur Mourão.Lisboa: Ediçôes 70, 2014.

BAUMAN, Zygmunt. Vida para consumo: a transformação das pessoas em mercadoria. Tradução de Carlos Alberto Medeiros Rio de Janeiro: Zahar, 2008.

BBC. British Broadcasting Corporation. Burberry burn bags, clothes and perfume worth millions. Disponível em: https://www.bbc.com/news/business-44885983. Acesso em: 22 fev. 2019.

BURBERRY. Annual Report 2015/2016. Disponível em: https://www.burberryplc. com/content/dam/burberry/corporate/Investors/Results_Reports/2016/5-annual_ report_2015_16/Report_burberry_annual_report_2015-16.pdf. Acesso em: 22 fev. 2019a.

BURBERRY. Our history. Disponível em: https://us.burberry.com/our-history/. Acesso em: 22 fev. 2019b. 
BURBERRY. Press Release. 6/9/2018 Disponível em: https:/www.burberryplc.com/en/ news-and-media/press-releases/corporate/2018/burberry-ends-practice-of-destroyingunsaleable-products.html. Acesso em: 23 fev. 2019c.

BURBERRY-B Annual Report. 2018. Disponível em: https://www.burberryplc. com/content/dam/burberry/corporate/Investors/Results_Reports/2018/Burberry_ AnnualReport_FY17-18.pdf Acesso em: 20 fev. 2019d.

ELLEN MACARTHUR FOUNDATION. Participants. DIsponível em: https://www. ellenmacarthurfoundation.org/our-work/activities/make-fashion-circular/participants. Acesso em: 21 fev. 2019.

GREENPEACE. Burberry commits to toxic-free fashion. Disponível em: https://www. greenpeace.org/archive-international/en/press/releases/2014/Burberry-commits-totoxic-free-fashion/. Acesso em: 20 fev. 2019.

INFOMONEY. Burberry queima 141 milhöes em produtos. https://www.infomoney. com.br/negocios/grandes-empresas/noticia/7528628/burberry-queima-141-milhoesprodutos-ano-pratica-comum-mercado-luxo. Acesso em: 22 de fev 2019.

LIPOVETSKY, Gilles. Felicidade paradoxal: ensaio sobre a sociedade do hiperconsumo. Tradução de Patrícia Xavier. 2. ed. Lisboa: Edições 70, 2006.

L'OFFICIEL. Grandes marcas assinam acordo para uma moda mais sustentável. Disponível em: https://www.revistalofficiel.com.br/moda/grandes-marcas-de-modaassinam-acordo-para-uma-moda-mais-sustentavel. Acesso em: 21 fev. 2019.

POLANYI, Karl. A grande transformação. Rio de Janeiro: Elsevier/Campus, 2012

SIQUEIRA, José Eduardo de. Irreflexão e a banalidade do mal no pensamento de Hannah Arendt. Bioethikos, São Camilo, v. 4, n. 5, p.392-400, 30 jun. 2011

STELZER, Joana. Direito do Comércio Internacional: do Free Trade ao Fair Trade. Curitiba: Juruá, 2018.

THE GUARDIAN. Burberry to stop burning unsold items after green criticism. Disponível em: https:/www.theguardian.com/business/2018/sep/06/burberry-to-stopburning-unsold-items-fur-after-green-criticism. Acesso em: 22 fev. 2019.

THE NATIONAL. Bonfire of the vanities: Why Burberry's admission it burns unsold stock might just help the fashion industry. Disponível em: https://www.thenational. ae/lifestyle/fashion/bonfire-of-the-vanities-why-burberry-s-admission-it-burns-unsoldstock-might-just-help-the-fashion-industry-1.755700. Acesso em: 23 fev. 2019.

THE NEW PLASTICS ECONOMY GLOBAL COMMITMENT. Global Commitment: a line in the sand: Global Commitment to eliminate plastic pollution 
at its source. Disponível em: https://newplasticseconomy.org/projects/globalcommitment. Acesso em: 26 fev. 2019.

THE TRUE COST. Direção: Andrew Morgan. Produção: Michael Ross. País: Estados Unidos da América. 2015 (92min). Disponível em: https://www.netflix.com/br/ title/80045667. Acesso em: 2 mar. 2019.

UNITED NATIONS. Indice Multidimensional de Pobreza de 2019. Disponível em: https://news.un.org/pt/story/2019/07/1679661. Acesso em: 17 set. 2019.

WEINBERG, Lindsay. Burberry Receives Backlash for Burning \$38 Million of Unsold Products. 7/25/2018. Disponível em: https://www.hollywoodreporter.com/news/ burberry-receives-backlash-burning-38-million-unsold-products-1129922. Acesso em: 22 fev. 2019. 